\section{Dr. Lubrano, et al reply}

To the Editor:

We have read the letter of Dr. Scarpa ${ }^{1}$. Our editorial was written as a proposal for a different vision of psoriatic arthritis (PsA), a multifaceted syndrome, in the light of a better treatment stratification, and more in general, personalized medicine ${ }^{2}$.

In our editorial, we pointed out that PsA, because of its phenotypic complexity, could be better identified and managed as a syndrome, stimulating the reader to think of this condition as a combination of symptoms and signs that together represent a disease process ${ }^{2}$.

Indeed, we are aware that the pathogenesis, at present, is unique for all manifestations of $\mathrm{PsA}^{3}$ and we did not mention that the term syndrome means different pathogenesis of the various manifestations of PsA.

However, PsA belongs to the group of spondyloarthritis (SpA), a wide spectrum or a constellation of diseases with some common genetic background ${ }^{4,5}$ and it is potentially a separate disease of this group or a major characteristic of the same disease ${ }^{6}$.

As a similar condition, Behçet disease has been identified as a syndrome because of its potential complexity, and using this definition can help with disease management ${ }^{7}$.

Finally, we hope that our proposal to identify PsA as a syndrome could be of some interest, to provide better treatment management toward a target-to-treat strategy ${ }^{8}$. This is not a step back but a step forward to implement our knowledge and management of PsA.

ENNIO LUBRANO (D, MD, PhD; SILVIA SCRIFFIGNANO (D), MD; FABIO MASSIMO PERROTTA (D), MD, PhD, Dipartimento di Medicina e Scienze della Salute Vincenzo Tiberio, Università degli Studi del Molise, Campobasso, Italy. Address correspondence to Dr. E. Lubrano, Associate
Professor of Rheumatology, Dipartimento di Medicina e di Scienze della Salute Vincenzo Tiberio, Università degli Studi del Molise,

Via Giovanni Paolo II, C/da Tappino, 86100 Campobasso, Italy. E-mail: enniolubrano@hotmail.com

\section{REFERENCES}

1. Scarpa R. Psoriatic syndrome or psoriatic disease? J Rheumatol 2020;47:941.

2. Lubrano E, Scriffignano S, Perrotta FM. Psoriatic arthritis, psoriatic disease, or psoriatic syndrome? J Rheumatol 2019;46:1428-30.

3. Veale DJ, Fearon U. The pathogenesis of psoriatic arthritis. Lancet 2018;391:2273-84.

4. Garg N, van den Bosch F, Deodhar A. The concept of spondyloarthritis: where are we now? Best Pract Res Clin Rheumatol 2014;28:663-72.

5. Burgos-Varga R, Wei JC, Rahman MU, Akkoc N, Haq SA, Hammoudeh M, et al. The prevalence and clinical characteristics of nonradiographic axial spondyloarthritis among patients with inflammatory back pain in rheumatology practices: a multinational, multicenter study. Arthritis Res Ther 2016;18:132.

6. Nash P, Mease PJ, Braun J, van der Heijde D. Seronegative spondyloarthropathies: to lump or split? Ann Rheum Dis 2005;64 Suppl 2:ii9-13.

7. Yazici H, Seyahi E, Hatemi G, Yazici Y. Behçet syndrome: a contemporary view. Nat Rev Rheumatol 2018;14:119.

8. Lubrano E, Perrotta FM. Psoriatic arthritis: is it time to treat-to-target or target to treat? Clin Rheumatol 2017;36:2633-5.

First Release May 1 2020; J Rheumatol 2020;47:6;

doi: $10.3899 /$ jrheum. 200090 